\title{
SHORT PEPTIDES - SOMATOSTATIN ANALOGUES AS VECTOR FRAGMENTS IN THE DESIGN OF TARGET-ORIENTED CONJUGATES FOR RADIOPHARMACEUTICALS
}

\author{
D.S. Khachatryan ${ }^{1,2}$, A.V. Kolotaev ${ }^{1,2}$ \\ ${ }^{1}$ NRC «Kurchatov Institute» - IREA, 107076, Russia, Moscow, Bogorodskyval, 3. \\ ${ }^{2} \mathrm{NRC}$ «Kurchatov Institute», 123182, Russia, Moscow, AkademikaKurchatova pl., 1. \\ DOI: 10.19163/MedChemRussia2021-2021-72 \\ E-mail:derenik-s@yandex.ru
}

Nowadays, nuclear medicine technologies related to the use of radioactive sources for diagnostic and therapeutic purposes are under intensive development and implementation. There are about 190 radio diagnostic methods used in world medical practice. In Russia, unfortunately, only 22 methods are used in practical medicine. The annual production of radiopharmaceuticals meets the needs of the Russian Federation only by 1-3 percent.

In nuclear medicine, radiopharmaceuticals (RPh) play a major role in carrying out minimally invasive diagnostic and treatment procedures. The use of radiopharmaceuticals based on peptide carriers increases the effectiveness of early diagnosis, treatment and monitoring of treatment of a number of tumors, such as breast, uterine, ovarian, liver and prostate cancer.

Somatostatin and its analogues have a high affinity for somatostatin receptors, that are overexpressed in large quantities in neuroendocrine tumors, which makes them perfect candidatesfor target vectors. A number of conjugates - somatostatin analogs with chelators have been developed and used: DOTA-TATE, DOTA-TOC, DOTA-NOC, DOTA-OC. They are successfully used fordiagnosis (positron emission tomography) and therapy of neuroendocrine tumors. Nevertheless, the intensive search continues for new effective RPh with chelators forming more stable complexes with radionuclides as well as with peptides with greater selectivity to tumor cells.

The report presents the research conducted together with the Department of Radiochemistry of the Lomonosov Moscow State University in the field of RPh developments, an example of one of them is given below:

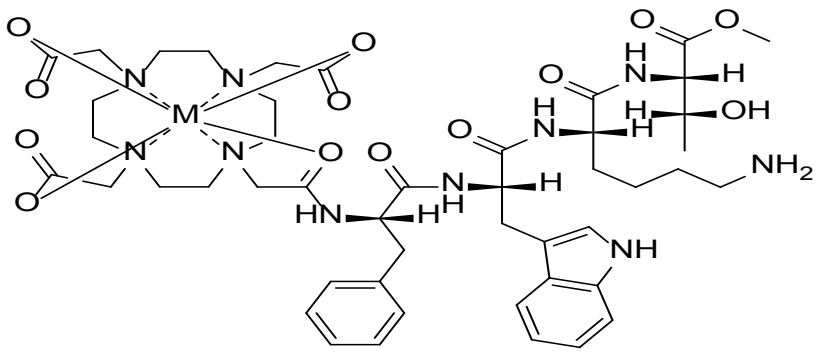

Figure 1. The analogue of somatostatin hormone conjugated with DOTA, containing the following radionuclides: $\mathrm{M}={ }^{44} \mathrm{SC},{ }^{64 / 67} \mathrm{Cu},{ }^{67 / 68} \mathrm{Ga},{ }^{90} \mathrm{Y},{ }^{177} \mathrm{Lu},{ }^{213} \mathrm{Bi}$ 